Interactive comment on "Satellite inference of water vapor and aerosol-above-cloud combined effect on radiative budget and cloud top processes in the Southeast Atlantic Ocean" by Lucia T. Deaconu et al.

Lucia T. Deaconu et al.

lucia.deaconu@physics.ox.ac.uk

Received and published: 24 July 2019

\title{
Dear Sir/Mam,
}

Please find attached a copy of the manuscript with all the corrections made for the review process.

Yours sincerely, 
Please also note the supplement to this comment:

ACPD

https://www.atmos-chem-phys-discuss.net/acp-2019-189/acp-2019-189-AC4-

supplement.pdf

Interactive comment on Atmos. Chem. Phys. Discuss., https://doi.org/10.5194/acp-2019-189,

Interactive 2019.

comment 